Kredo 3 (2020)
KREDO: Jurnal Ilmiah Bahasa dan Sastra
Terakreditasi Sinta 4 berdasarkan Keputusan Direktorat
Jenderal Penguatan Riset dan Pengembangan,
Kementerian Riset, Teknologi dan Pendidikan Tinggi
Republik Indonesia
Nomor: 23/E/KPT/2019. 08 Agustus 2019
https://jurnal.umk.ac.id/index.php/kredo/index

\title{
LINGUISTIK LANSKAP DI BALI: TANDA MULTILINGUAL DALAM PAPAN NAMA RUANG PUBLIK
}

\author{
Dwi Windah Wulansari \\ Email: dwiwindah_wulansari@yahoo.co.id
}

Program Studi Ilmu Linguistik, Fakutas Ilmu Budaya, Universitas Airlangga

Info Artikel

Sejarah Artikel Diterima 29 Februari

2020

Disetujui 15 mei 2020

Dipublikasikan 20

Mei 2020

\section{Keywords}

bali, multilingual, public spaces, tourists Kata Kunci bali, multibahasa, ruang publik, turis
: : Balinese people can be accepted as invited people. This study uses qualitative research methods, namely by taking a number of photo signs relating to places to eat, religious places, places of business, and street names. From the results of research on English, the most widely used on the nameplate on the island of Bali, followed by Indonesian, Balinese, and Chinese. This is common because there are many tourists who go on holiday on the island of Bali, therefore English is very dominantly used, but the Balinese also use the Balinese script on the street sign, in order to maintain this character from extinction.

Penelitian ini bertujuan untuk mengetahui bahasa yang digunakan di ruang publik yang terdapat di Pulau Bali. Pulau Dewata Bali dipilih karena merupakan pulau yang banyak dikunjungi - oleh turis domestik maupun mancanegara, masyarakat Bali dapat dikatakan sebagai masyarakat yang multibahasa. Penelitian ini menggunakan metode penelitian kualitatif, yaitu dengan mengambil beberapa foto papan nama yang berhubungan dengan tempat makan, tempat keagamaan, tempat usaha, dan nama jalan. Dari hasil penelitian menyebutkan bahwa Bahasa Inggris paling banyak digunakan dalam papan nama di pulau Bali, dilanjutkan dengan Bahasa Indonesia, aksara Bali, dan aksara Cina. Hal ini lumrah terjadi mengingat banyak turis yang dating untuk berlibur di pulau Bali, oleh karena itu Bahasa Inggris sangat dominan digunakan, namun masyarakat Bali juga menggunakan Aksara Bali dalam papan nama jalan, guna untuk mempertahankan aksara tersebut agar tidak punah. 


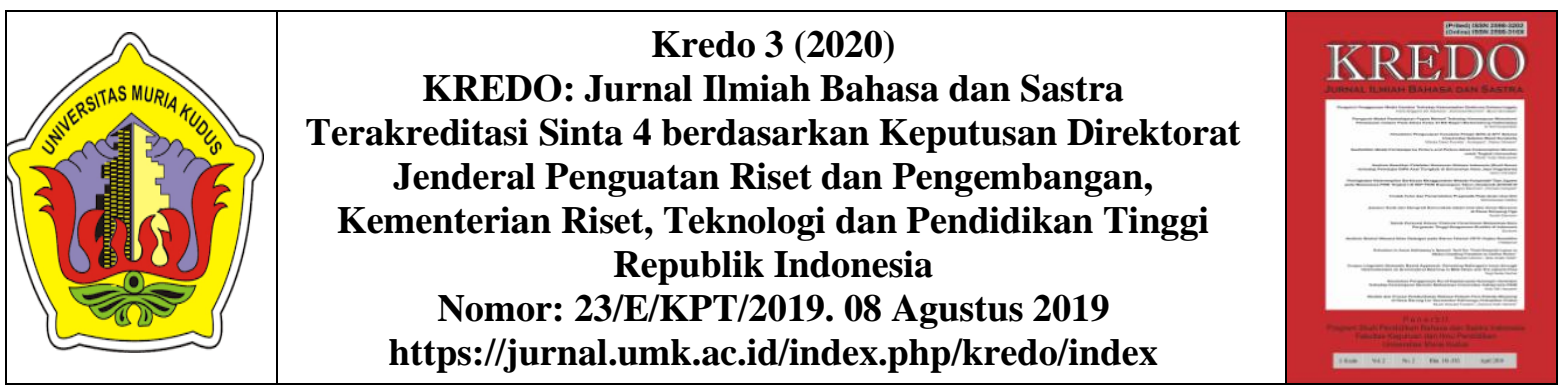

\section{PENDAHULUAN}

Satu wilayah sangat mungkin terjadi adanya beberapa variasi bahasa yang tumbuh dan berkembang secara berdampingan sehingga bentuk interaksinya mengarah ke alih kode dan campur kode. Hal tersebut terjadi karena masyarakat melakukan interkasi secara multilingual.

Bali atau yang dikenal juga dengan Pulau Dewata, dapat dikatakan sebagai pulau yang terdapat beragam bahasa yang digunakan karena merupakan salah satu tempat wisata andalan di Indonesia. Bahkan orang-orang luar negeri lebih mengenal Bali daripada Indonesia. Hal ini tak lain dan tak bukan karena Bali memiliki potensi wisata (budaya dan alam) begitu hebatnya. Wisatawan baik dari domestik maupun mancanegara pun banyak yang berkunjung ke Bali. Tidak diragukan lagi Interaksi yang dilakukan oleh berbagai kelompok etnis menciptakan masyarakat multibahasa.

$$
\text { Wardhaugh (2006: }
$$

menggunakan istilah multibahasa untuk merujuk pada situasi di mana seorang penutur memiliki kemampuan lebih dari satu bahasa. Hal itu tidak ditujukan dalam konteks lisan saja tetapi juga dalam tanda-tanda tertulis. Setiap orang yang tinggal di suatu tempat pasti akan dikelilingi oleh tanda-tanda tertulis, yang ditampilkan pada sebuah poster, nama jalan, pemberitahuan, pesan resmi, dan iklan dll (Xia \& Li, 2016).

Di Bali, tanda tertulis multibahasa dapat dengan mudah ditemukan, misalnya di tempat keagamaan, tempat wisata, pusat perbelanjaan, dan tempat makan. Mungkin ini menjadi salah satu hal yang ingin ditonjolkan dari Pulau Dewata Bali untuk menarik banyak orang dari berbagai negara, memberi kesan akan pulau Bali yang masih kental dengan budayanya, etnis, dan agama. Selain itu, multibahasa juga dapat dilihat dari penggunaan bahasanya, yang memiliki kemahiran berbahasa lebih dari satu bahasa yang digunakan sebagai tanda diruang publik.

Jika kita perhatikan, bagaimana bahasa-bahasa tersebut dipilih untuk dituliskan pada teks-teks di ruang publik. Terdapat beberapa macam bahasa seperti bahasa daerah, bahasa Indonesia, bahasa Inggris, atau bahasa yang bersifat bilingual yang merupakan perpaduan bahasa (Indonesia-Inggris dan sebaliknya, Indonesia-Bali dan sebaliknya). Dan teks-teks yang menggunakan aksara aslinya seperti aksara Bali.

Meskipun penggunaan bahasa Indonesia di ruang publik sudah diatur secara jelas dalam UU RI No 24 Tahun 2009 tentang Bendera, Bahasa, dan Lambang Negara, serta Lagu Kebangsaan, faktanya dalam praktik dan implementasi sangat berbeda. Beberapa studi yang telah dilakukan oleh beberapa peneliti membenarkan bahwa alasan ekonomi menjadi faktor utama penggunaan bahasa asing (terutama bahasa Inggris) daripada bahasa Indonesia atau bahasa daerah (Kusumaningsih, Sudiatmi, \& Muryati, 2013; Riani, 2014; Wijana, 2014).

Makalah ini bertujuan untuk menganalisis tanda-tanda multibahasa di ruang publik yang terdapat di pulau Dewata Bali. Tujuannya, yaitu untuk menemukan bahasa sebagai tanda di ruang publik seperti di pusat perbelanjaan, tempat makan, tempat ibadah, dan untuk menunjukkan bahasa apa yang paling banyak digunakan di ruang pablik yang terdapat di Pulau Dewata Bali. 


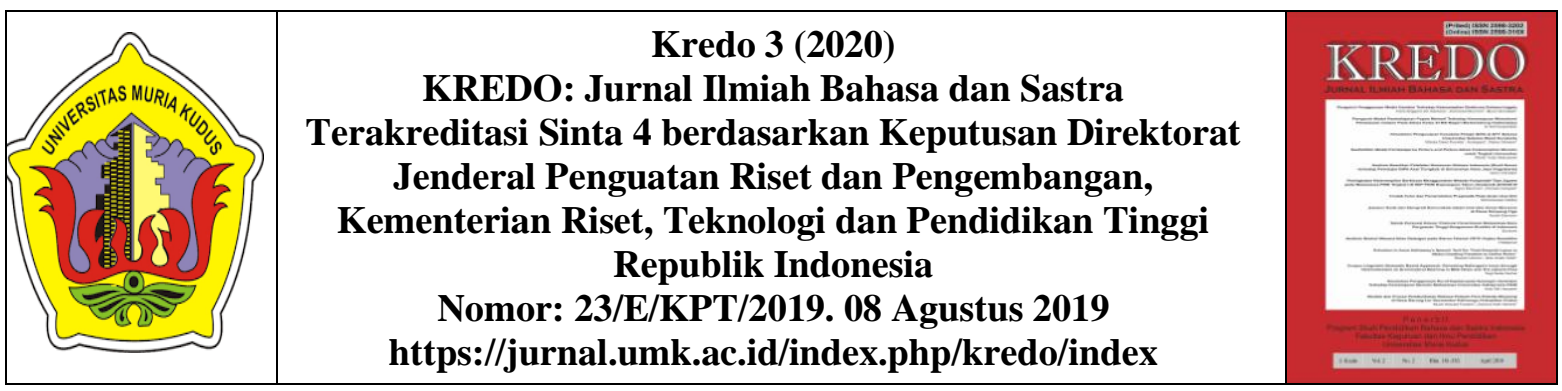

\section{KAJIAN TEORI}

Dalam dekade terakhir, muncul disiplin ilmu yang disebut dengan lanskap linguistik (linguistics lancape/linguistics city scape). Kajian ini merupakan cabang dari ilmu sosiolinguistik. Karena kita dapat melihat adanya gejala bahasa dan gejala sosial pada masyarakat multietnik yang muncul di masyarakat. Lanskap linguistik (yang selanjutnya disingkat LL) merupakan kajian yang berfokus pada penggunaan bahasa di ruang publik, baik monolingual, bilingual, maupun multilingual.

LL memberikan informasi mengenai perilaku sosiolinguistik dengan membandingkan penggunaan bahasa pada tataran ruang resmi dan tidak resmi. Pada tataran resmi (official sign), teks-teks diproduksi oleh pemerintah yang selanjutnya dikenal sebagai konsep Top-Down dan pada tataran tidak resmi (non-official sign), teksteks diproduksi oleh swasta atau individu yang dikenalkan konsep bottom-up (Gorter, 2006; Backhaus,2007; BenRafael et al, 2006; Cenoz dan Gorter,2006; Blommaert, 2014). Selain penggunaan bahasa di ruang public, LL juga mengkaji penggunaan teks-teks tersebut pada area-area tertentu, yaitu area-area multilingual (Blommaert dan Maly, 2014)

Ben-Rafael et.al

(2006:14)

mendefinisikan lanskap linguistik lebih merujuk pada pengumuman tanda yang berlokasi di luar atau di dalam lembaga publik atau bisnis swasta di lokasi geografis tertentu. Gorter (2006) sendiri mengkategorikan tanda-tanda linguistik lanskap yaitu top-down (tanda-tanda resmi yang dikeluarkan oleh birokrasi publik) dan bottom-up (tanda-tanda non- resmi diposting oleh individu atau bisnis). Perbedaan utama antara dua kategori tersebut adalah pihak yang membuat tanda-tanda tersebut dan unsur-unsur dari lingusitik lanskap resmi dapat mencerminkan budaya yang dominan sementara yang dan dirancang non-resmi dibuat sesuai dengan strategi individu, bisnis misalnya (Ben-Rafael, 2006: 8).

Pendekatan ini sangat berguna untuk menjelaskan bagaimana teksteks tersebut hadir dan bagaimana teks-teks tersebut didistribusikan (menyebar) dalam populasi dan komunitas tertentu serta hubungan antarmereka atau pola interaksi di mana masyarakat ikut-serta pada ruang-ruang tertentu sehingga ada investigasi terkait relasi kuasa dalam suatu wilayah (Blommaert dan Maly, 2014).

Fungsi LL terbagi menjadi dua: fungsi informasi dan fungsi simbolik. Fungsi informasi merujuk pada teksteks yang diproduksi oleh pemerintah dan swasta/individu. Fungsi informasi lebih menekankan pada informasi yang diberikan kepada pembaca teks atas informasi yang diberikan oleh kedua pihak. Teks yang diproduksi oleh swasta/individu bersifat lebih beragam daripada teks yang diproduksi oleh pemerintah. Hal itu disebabkan karena kurangnya aturan yang mengatur pola teks-teks tersebut. Fungsi informasi merujuk pada informasi yang diberikan kepada pembaca atas nama tempat, informasi umum, nama barang dan jasa (Ardhian,2018:173) Selanjutnya, selain fungsi informasi, LL juga memiliki fungsi simbolik. Fungsi ini menandai simbol-simbol yang dihasilkan dari kemunculan perilaku teks-teks tersebut. 


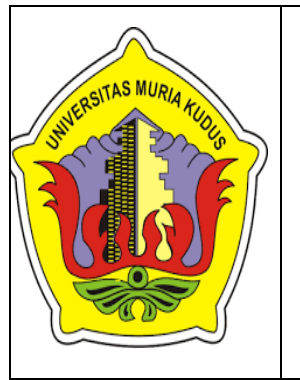

Kredo 3 (2020)

KREDO: Jurnal Ilmiah Bahasa dan Sastra

Terakreditasi Sinta 4 berdasarkan Keputusan Direktorat

Jenderal Penguatan Riset dan Pengembangan,

Kementerian Riset, Teknologi dan Pendidikan Tinggi

Republik Indonesia

Nomor: 23/E/KPT/2019. 08 Agustus 2019

https://jurnal.umk.ac.id/index.php/kredo/index

Secara spesifik, konsep LL merujuk pada bahasa tanda jalan umum, papan iklan, nama jalan dan tempat, tanda kedai atau toko komersial, dan tanda umum bangunan pemerintah yang berkombinasi membentuk LL suatu wilayah, kawasan atau perkotaan (urban agglomeration). LL merujuk pada teks yang sudah tersaji dan terbentangkan di ruang publik. Dengan kata lain, penelitian LL menyelidiki pemakaian bahasa tulis di ruang public (public uses of written languages).

Fungsi simbolik mengacu pada kebijakan bahasa, imperialisasi bahasa, marjinalisasi bahasa, diskriminasi bahasa, dan faktor-faktor sosial yang menyebabkannya (Ardhian 2018:173). Faktor sosial yang dimaksud adalah relasi budaya, identitas kelompok (etnik, gender, status sosial), relasi kuasa (ekonomi, politik, demografi), dan status bahasa (bahasa resmi dan tidak resmi).

Pendekatan ini sangat berguna dalam menjelaskan bagaimana teks-teks tersebut hadir dan bagaimana teksteks tersebut didistribusikan (menyebar) dalam populasi dan komunitas tertentu serta pola interaksi di mana masyarakat ikut serta pada aktifitas di ruang-ruang tertentu sehingga ada investigasi terkait relasi kuasa dalam suatu wilayah (Blommaert dan Maly, 2014)

Ada beberapa studi terkait guna menopang penelitian ini, Pertama dilakukan oleh Coluzzi dan Kitade (2015) yang berjudul The languages of places of worship in the Kuala Lumpur area: a study on the religious linguistic landscape in Malaysia. Kedua dilakukan oleh Wafa (2018) berjudul Signs of Multilingualism at Religious Places in Surabaya: A Linguistic Landscape Study. Ketiga, penelitian yang dilakukan oleh Eko Widianto (2018) berjudul Pemertahanan Bahasa Daerah Melalui Pembelajaran Dan Kegiatan Di Sekolah.

Penelitian ini sangat menarik untuk diteliti mengingat bahwa Pulau Dewata Bali merupakan tempat wisata yang banyak dikunjungi turis mancanegara, terdapat berbagai macam multibahasa di Bali, sehingga tanda-tanda di ruang publik seperti tempat makan, pusat perbelanjaan, pemberitahuan menggunakan bahasa Asing agar para turis mengerti dengan apa yang di yang dituliskan oleh masyarakat Bali.

\section{METODE PENELITIAN}

Metode penelitian ini adalah kualitatif. Pada penelitian ini, peneliti mengambil sumber data papan nama yang terdapat di Pulau Dewata Bali. Sumber data diambil dengan mengambil beberapa foto di beberapa tempat di Bali. Peneliti juga mewawancarai beberapa pemandu wisata di Bali untuk memperoleh informasi mengenai keanekaragaman bahasa, budaya, dan tradisi yang terdapat di Pulau Bali. Fotofoto tersebut lalu diklasifikasikan berdasarkan tempat keagamaan, tempat makan, tempat wisata, tempat usaha, dan nama jalan. Analisis lebih mendalam, penelitian ini dianalisis menggunakan pendekatan linguistik lanskap. 


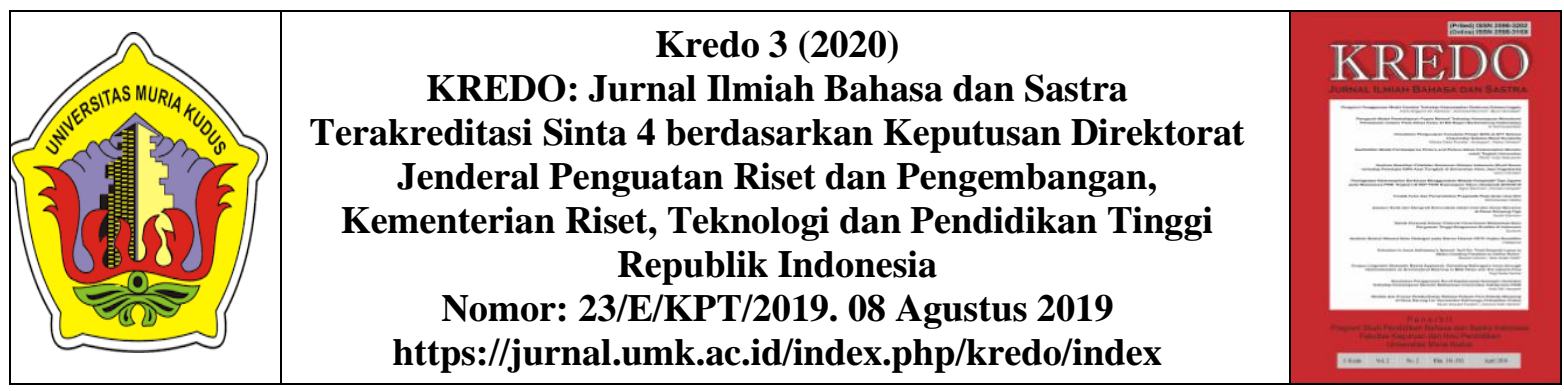

HASIL DAN PEMBAHASAN

\section{Papan Nama di Tempat Keagamaan}

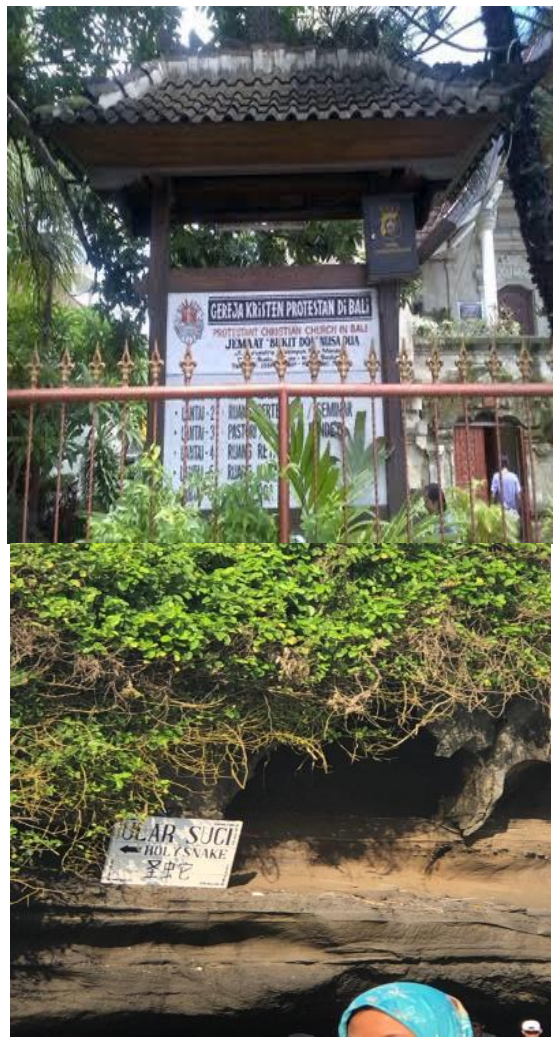

Gambar 1 Papan nama yang terdapat di tempat keagamaan

Seperti yang sudah ditunjukkan diatas bahwa bahasa atau tanda multilingual yang digunakan masyarakat Bali untuk papan nama di lingkungan tempat keagamaan dengan menggunakan bahasa indonesia (monolingual) selanjutnya diikuti dengan bahasa inggris dan aksara cina (bilingual). Hal ini dimaksudkan agar turis mancanegara maupun domestik dapat mengerti dengan apa yang dihimbau atau diberitahukan dalam papan nama tersebut. Bahasa Inggris dipilih karena merupakan bahasa internasional dan sebagian besar turis pasti mengerti jika menggunakan bahasa Inggris.

424 | Jurnal Kredo Vol. 3 No. 2 April 2020
Penggunaan bahasa Inggris di seluruh dunia menandakan pengaruh globalisasi yang mengarah pada prinsipprinsip ekonomi seperti pemasaran, produksi, dan konsumsi. Sedangkan bahasa Indonesia dipilih karena Pulau Bali merupakan salah satu Pulau yang berada di Indonesia, oleh karena itu bahasa nasional masyarakat Bali adalah Bahasa indonesia. Kendati bahasa Indonesia dipakai sebagai basantara (lingua franca), saat ini dapat dikatakan bahwa Indonesia mirip dengan negara lain di dunia, dalam arti bahwa ia dipengaruhi oleh proses globalisasi yang sering dikaitkan dengan merebaknya bahasa Inggris.

Pemakaian bahasa asing utamanya bahasa Inggris ini setidaknya menuntut pembaca untuk berusaha memahami konten pesan yang tersaji dalam tanda atau rambu di ruang pubik. Multibahasa jarang digunakan dengan menggunakan satu tanda atau satu bahasa.

\section{Papan Nama di Tempat Makan}

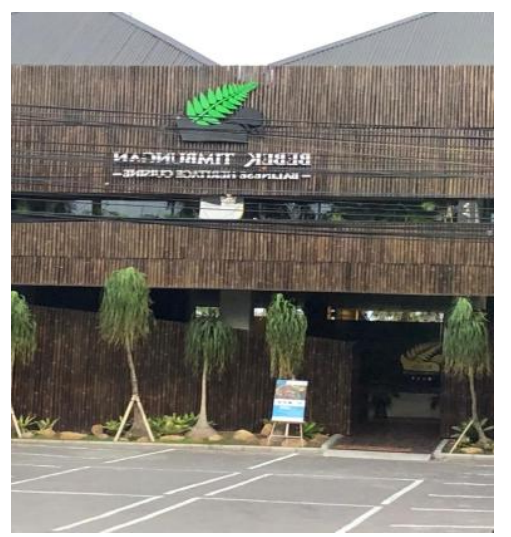



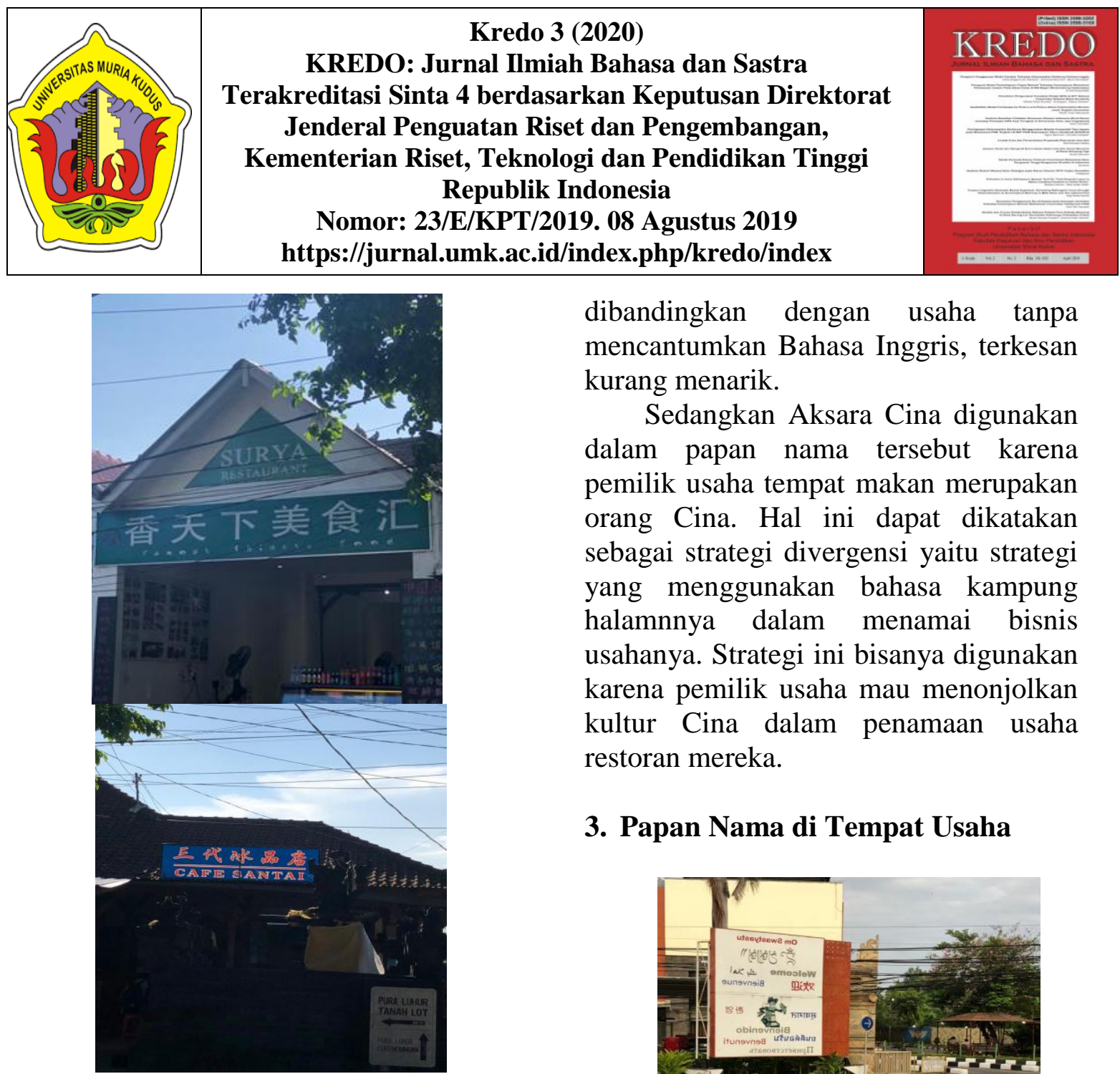

dibandingkan dengan usaha tanpa mencantumkan Bahasa Inggris, terkesan kurang menarik.

Sedangkan Aksara Cina digunakan dalam papan nama tersebut karena pemilik usaha tempat makan merupakan orang Cina. Hal ini dapat dikatakan sebagai strategi divergensi yaitu strategi yang menggunakan bahasa kampung halamnnya dalam menamai bisnis usahanya. Strategi ini bisanya digunakan karena pemilik usaha mau menonjolkan kultur Cina dalam penamaan usaha restoran mereka.

\section{Papan Nama di Tempat Usaha}

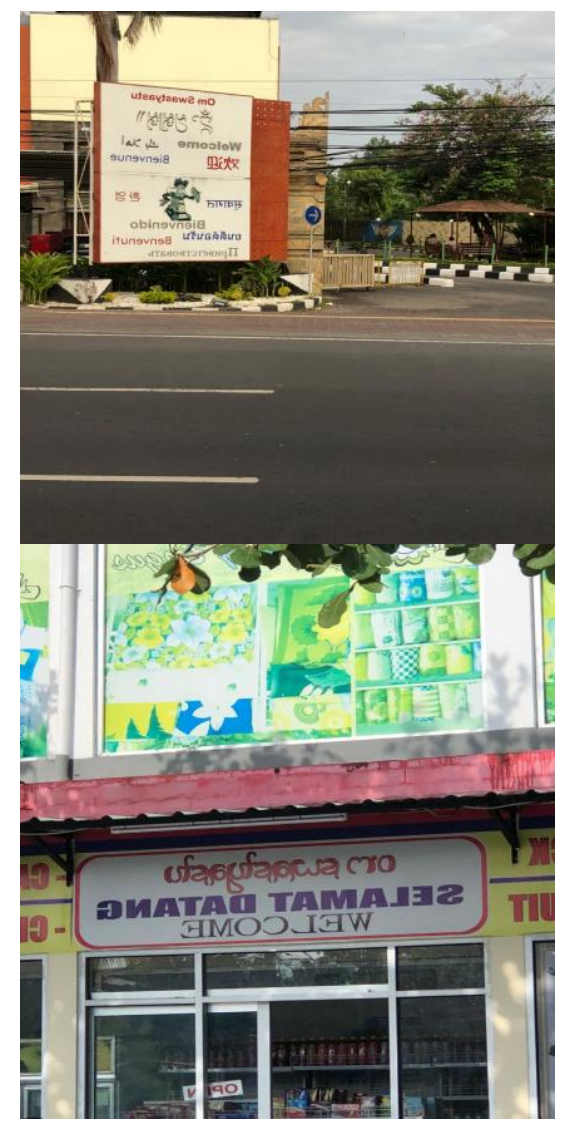

oleh beberpa pemilik usa nama yang mereka buat. Agar turis menegtahui apa yang mereka jual dan hal tersebut merupakan strategi pemasaran bagi pemilik usaha, 

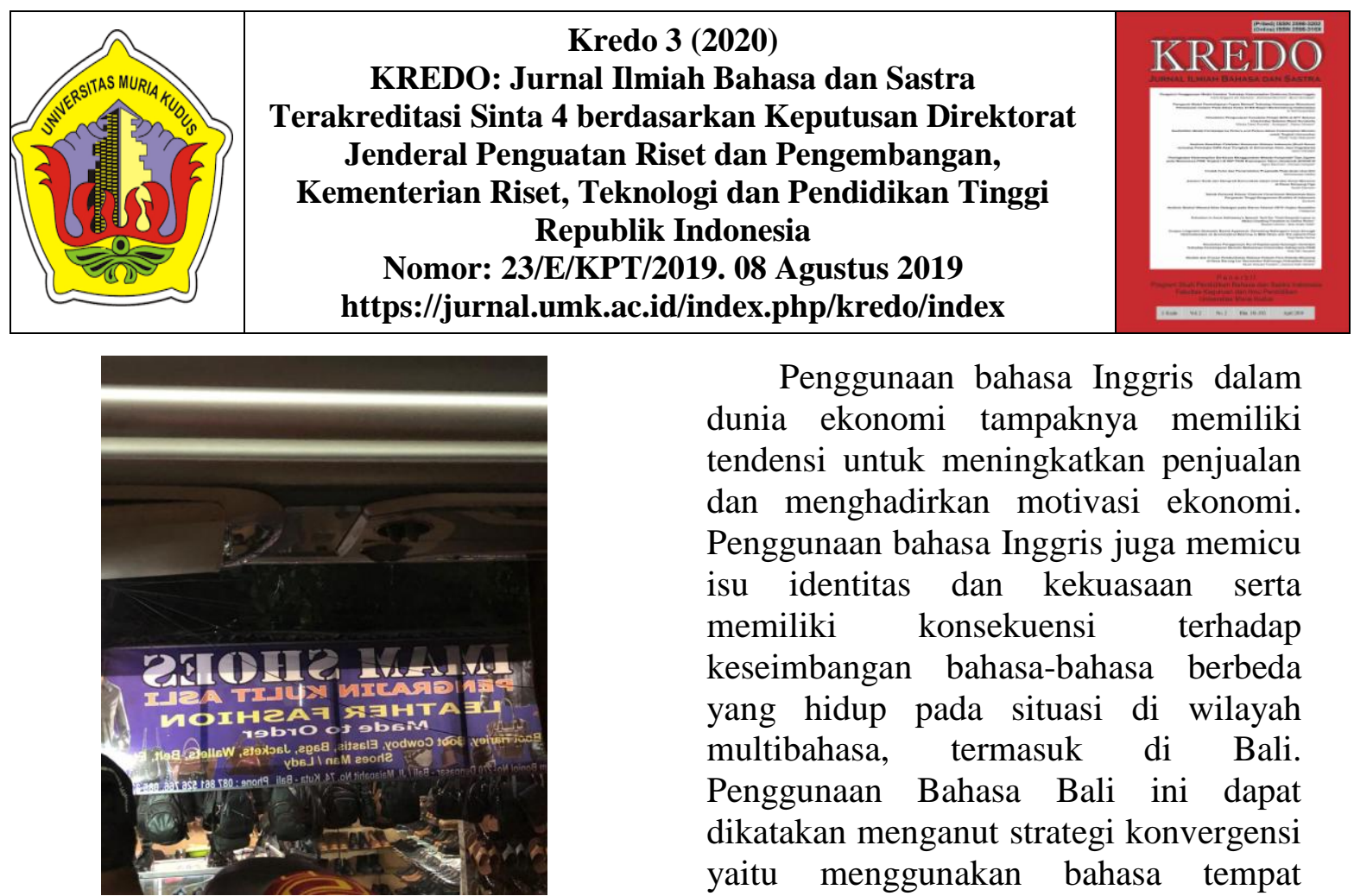

Penggunaan bahasa Inggris dalam dunia ekonomi tampaknya memiliki tendensi untuk meningkatkan penjualan dan menghadirkan motivasi ekonomi. Penggunaan bahasa Inggris juga memicu isu identitas dan kekuasaan serta memiliki konsekuensi terhadap keseimbangan bahasa-bahasa berbeda yang hidup pada situasi di wilayah multibahasa, termasuk di Bali. Penggunaan Bahasa Bali ini dapat dikatakan menganut strategi konvergensi yaitu menggunakan bahasa tempat rantaunya, karena seperti yang kita ketahui tak sedikit turis domestik ataupun mancanegara yang mendirikan tempat usaha di Bali.

Bali juga menjadi pilihan beberapa orang untuk dijadikan tempat rantau. Bahkan tak sedikit artis ibukota yang mendirikan tempat makan dan hotel di Bali. Hal ini dilakukan agar masyarakat rantau dapat berbau dengan masyarakat Bali. Dan tujuan utama pengguanaan bahasa Bali agar bahasa tersebut tidak punah digerus zaman dan kemodernan bahasa saat ini.

\section{Papan Nama pada Nama Jalan}

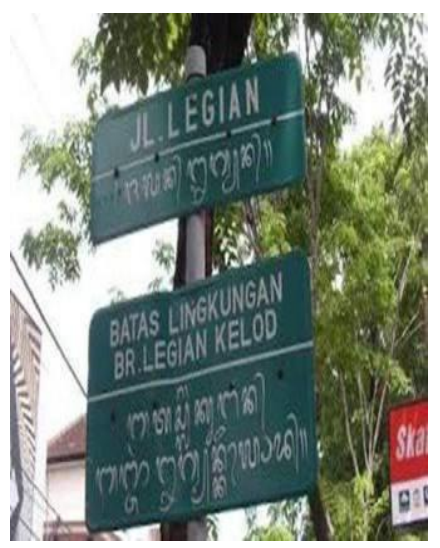
menggunakan Bahasa Inggris terlebih dahulu kemudian menggunakan Bahasa Indonesia atau Bahasa Bali. 


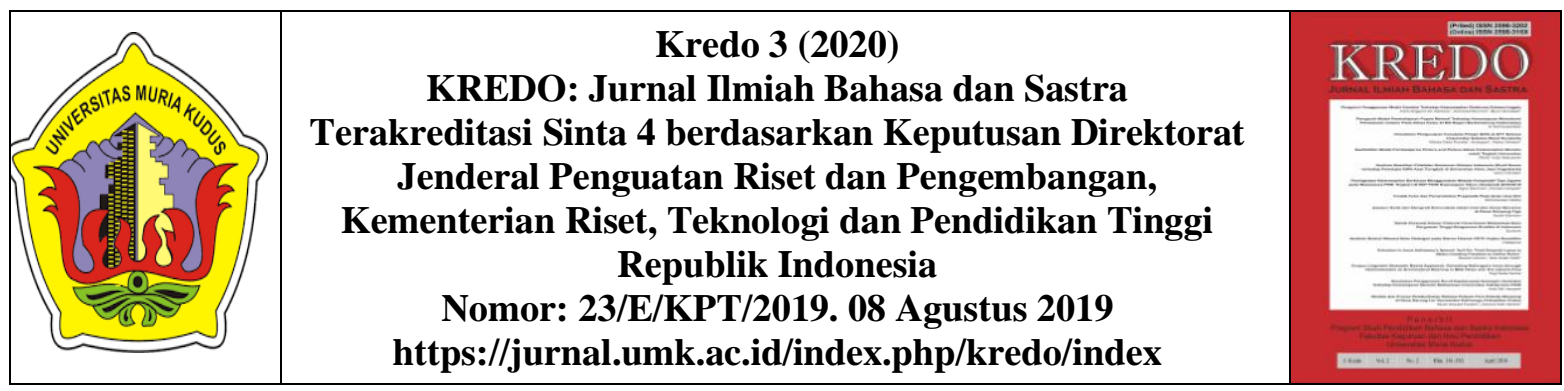

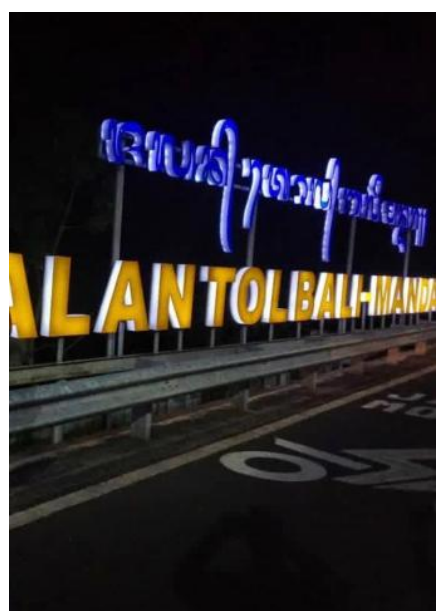

Gambar 4 papan nama yang terdapat pada nama jalan

Dalam tabel 4, menujukkan papan nama yang dipasang untuk nama jalan yang ada di Bali. Papan nama ini biasanya menggunakan Aksara Bali, diikuti dengan Bahasa Indonesia tanpa menggunakan Bahasa Internasioanal atau Bahasa Inggris. Aksara Bali dipilih untuk mengenalkan bahasa Bali sekaligus menujukkan bahwa masyarakat Bali sangat menjaga budaya dan bahasanya. Menurut hasil wawancara, papan nama jalan ditulis dengan menggunakan Bahasa Bali untuk memperlihatkan pada turis aksara Bali bilamana mereka mau belajar aksara Bali. Dan memang benar, menurut beberapa pemandu wisata, para turis suka dan ingin mempelajari bahasa Bali. Tujuan utama Bahasa Bali digunakan juga untuk mempertahankan bahasa itu sendiri.

\section{SIMPULAN}

Berdasarkan hasil penelitian diatas, dapat disimpulkan bahwa Bahasabahasa asing seperti bahasa Inggris dan bahasa Tionghoa lebih mendominasi lanskap di Indonesia, khususnya di Bali yang merupakan pulau yang memiliki memiliki bermacam-macam bahasa yang berkembang karena beberapa faktor. Seperti faktor ekonomi, budaya, dan sosial.

Faktor ekonomi menjadi salah satu faktor yang paling dominan dalam penggunaan bahasa internasional di Bali. Hal ini dikarenakan agar wisatawan lebih mudah dalam mengenali bahasa di ruang publik. Absennya bahasa-bahasa daerah yang menurut jumlah penuturnya merupakan bahasa mayoritas di wilayah tersebut tidak kalah penting digalakkan oleh masyarakat Bali. Masyarakat Bali memperkenalkan penggunaan bahasa Bali di ruang pablik

Bahasa Inggris digunakan karena merupakan Bahasa Internasional. Diikuti dengan Bahasa Indonesia, Aksara Bali, dan Aksara Cina. Bahasa Indonesia merupakan bahasa nasional republik Indonesia dan Bali merupakan salah satu Pulau yang terdapat di Indonesia, Aksara Cina biasanya digunakan dalam papan nama usaha, sedangkan Aksara Bali digunakan dalam papan nama jalan merupakan salah satu cara masyarakat Bali dalam menjaga budaya dan mempertahankan aksara Bali itu sendiri.

Dikala anak muda sekarang banyak yang berbondong-bondong mempelajari bahasa Inggris, tentu bahasa daerah tidak boleh dilupakan, Aksara Bali juga harus dilestarikan dan dipertahankan keberadaannya, jangan sampai turis mancanegara mempelajari dan mahir dalam berbahasa dan menulis aksara Bali, namun masyarakat Bali malah tidak mau mempelajari aksara Bali. 


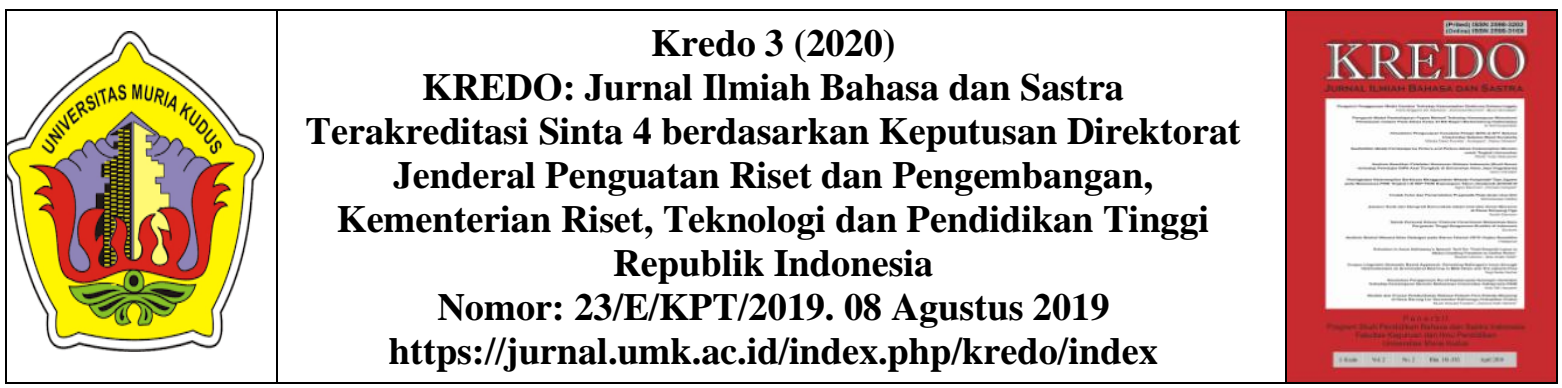

\section{DAFTAR PUSTAKA}

Ardhian, Dany dan Soemarlam. 2018. Mengenal Kajian Lanskap Linguistik Dn Upaya Penataannya Dalam RuangRuang Publik Di Indonesia. Jurnal Akrab Juara. 3(3), 170181.

Akindele, D. O. 2011. Linguistic Landscapes as Public Communication: A Study of Public Signage in Gaborone Botswana. International Journal of Linguistics, 3(1), 111.

Aribowo, E. K. 2017. Linking Arabic, Islam, and Economy: Onomastics on Bussiness Name of People of Arab Descent in Indonesia. KARSA: Journal of Social and Islamic Culture, 25(2), 284- 306.

Badan Pengembangan dan Pembinaan Bahasa dan Kementerian Pendidikan dan Kebudayaan. 2011. Undang-undang Republik Indonesia nomor 24 Tahun 2009 tentang Bendera, Bahasa, dan Lambang Negara, serta Lagu Kebangsaan. Jakarta.

Botterman, A.K. 2011. Linguistic Landscapes in the City of Ghent: An Ampirical Study. Universiteit Gen: Dissertation.

Blommeart, J., dan Ico, M. 2014. Ethnographic Linguistic

Landscape Analysis and Social Change: A Case Study. Tilburg University: Tilburg Papers in Culture Studies.

Coluzzi, Paolo dan Rie Kitade. The languages of places of worship in the Kuala Lumpur area.
Linguistic Landscape, Vol. 1(3), 243-267

Dasuki, Sholeh. 2015. Pemakaian Bahasa Indonesia dalam Ruang Publik di Kota Surakarta. Seminar Nasional Pendidikan Bahasa Indonesia. ISSN:2477636x, 225-266.

Gorter, D., \& Cenoz, J. 2007. Knowledge about language and linguistic landscape. In N.H.Hornberger (Chief Ed.) Encyclopedia of Language and Education, 2nd revised edition, (pp. 1-13). Berlin: Springer Science.

Hendrastuti, Retno. 2015. Penggunaan Bahasa pada Ruang Publik di Kota Surakarta. Kandai. Volume 11 No. 1, 29-43.

Kusumaningsih, D., Sudiatmi, T., \& Muryati, S. 2013. Pengidonesiaan Kata dan Ungkapan Asing pada Nama Badan Usaha, Kawasan, dan Gedung. Jurnal Pendidikan, 22(3), 267-286.

Lillis, T., \& McKinney, C. 2013. The sociolinguistics of writingin a global context: Objects, lenses, consequences. Journal of Sociolinguistics, 17(3), 415439.

Mark, David M. 2011. Landscape in Language Transdisciplinary Perspective. Philadelphia: John Benjamins Publishing Co.

Moriarty, M. 2014. Contesting language ideologies in the linguistic landscape of an Irish tourist town. International Journal of Bilingualism, 18(5), 464-477. http://doi.org/10.1177/1367006 913484209. 
KREDO: Jurnal Ilmiah Bahasa dan Sastra

Terakreditasi Sinta 4 berdasarkan Keputusan Direktorat Jenderal Penguatan Riset dan Pengembangan, Kementerian Riset, Teknologi dan Pendidikan Tinggi Republik Indonesia

Nomor: 23/E/KPT/2019. 08 Agustus 2019 https://jurnal.umk.ac.id/index.php/kredo/index

Nash, J. 2016. Is linguistic landscape necessary?. Landscape Research. 41(3), 380-384.

Puzey, G. 2016. Renaming as CounterHegemony: The Cases of Noreg and Padania. Dalam G. Puzey, \& L. Kostanski, Names and Naming: People, Places, Perceptions, and Power (244272). Bristol: Multilingual Matters.

Riani. 2014. Dominasi Bahasa Inggris pada Nama Badan Usaha di Yogyakarta. Widyaparwa, 42(2), 141-152.

Wafa, Ali dan Sheila Wijayanti . 2018. Signs of Multilingualism at Religious Places in Surabaya: A Linguistic Landscape Study. Atlantis Press, International Conference on Language Phenomena in Multimodal Communication (KLUA 2018, 34-41.

Wardhaugh, R. 2006. An Introduction to Sociolinguistics. Oxford: Blackwell Publishing
Widianto, Eko. Pemertahanan Bahasa Daerah Melalui Pembelajaran Dan Kegiatan Di Sekolah. Jurnal Kredo, 1 (2), 1-13.

Wijana, I Dewa Putu. 2014. Bahasa, Kekuasaan, dan Resistansinya: Studi Tentang Nama-Nama Badan Usaha di Daerah Istimewa Yogyakarta. Humaniora. Volume 26 No. 1, 56-64. 2016. Bahasa dan Entnisitas: Studi Nama-nama Rumah Makan Padang. Masyarakat Linguistik Indonesia. Volume ke-34 No.2, 196-206.

Wolf, H.-G., Hans-Georg Wolf Zweitgutachter, H., Bernhard Bielick, H., \& Magdalena, A. 2012. English in the Linguistic Landscape of Hong Kong: A Case Study of Shop Signs and Linguistic Competence. Universität Potsdam. 